\title{
Empirical markers in the concept of digital logistics of multichannel supply chains
}

\author{
Mikhail Mikhaylyk ${ }^{1, *}$, Vera Baginova ${ }^{2}$, and Enver Mamaev ${ }^{1}$ \\ ${ }^{1}$ Rostov State Transport University, 2. The square of the Rostov Shooting Regiment of the National \\ Militia, 3440386 Rostov-on-Don, Russia \\ ${ }^{2}$ Russian University of Transport, Minayevskiy per., 2, 127055, Moscow, Russia
}

\begin{abstract}
The scientific paper is devoted to the identification of empirical features of the modern conceptualization of digital logistics in the conditions of the transition to a multichannel sales system. The authors conclude that the modern development of logistics is going through a serious stage of its rebirth, which is accompanied by a change in the market mechanics of the commodity supply system of the consumer market. The paper provides an evidence base of empirical and theoretical substantiation of changes in the operation of supply chains of the consumer market due to the transformation of the sales model and the transition from mono-channel to multichannel sales, which, as the authors believe, is not of evolutionary, but of revolutionary nature.
\end{abstract}

\section{Introduction}

For a long period of time, especially at the stage of transition to the market, economic theory and logistics outran the practice of developing the traditional spheres of reproduction and circulation, not all the problems of which were really solved. Today, the rapid growth of the digital economy stimulates the separation of logistical practice from the theory; a certain archaic nature of the previous methodological guidelines does not allow adequately reflecting the progressive market practice.

The present study identifies the causes and factors of the restructuring of the theoretical and methodological basis of modern logistics, the mobility of which must be adequate to the speed and radical nature of change of the processes that it is intended to describe and resolve. The issue of the development of modern multichannel sales contains a sufficiently critical mass of such changes that allow arguing this conclusion.

\section{Materials and Methods}

The problematic aspects of cooperative interaction of the commodity distribution network links, the market sustainability of supply chains and the formation of the resulting vector of their current market evolution in the domestic sphere of commodity circulation are the subject of quite important scientific and practical research in modern logistics.

\footnotetext{
*Corresponding author: mihailuk.m@gmail.com
} 
Modern institutional transformation of single-channel retail trade and the development of Internet commerce, which forms a new phase of its market cycle, received a thorough analysis in the scientific papers of such authors as: Albekova A. [1], Borisova V. [3], Vetrova E. [5], Voronova A. [6], Gasparyan V. [7], Lopatkin D., Sergeev V., Chernyshenko $\mathrm{M}$. and others, who made an attempt to assess how much the development of e-commerce and new communication channels form a balanced model for the development of a trading and retail system for the supply of consumer market. A common denominator of their research is an empirical confirmation of the growing role of e-commerce in the commodity producing network of the consumer market [1-24].

As part of this study, an attempt has been made to reveal the specifics of the empirical prerequisites and features of the formation of a new logistics concept in the context of the transition of modern trade to a multichannel sales system, the revolutionary and extremely complex nature of which should be properly reflected in the system of modern scientific knowledge.

\section{Results}

Based on the results of the study, let us designate a number of the most significant trends and institutional and market transformations in the commodity supply system of the consumer market, which will determine in the future a new perspective and vector of construction - restructuring of logistic scientific knowledge.

1. Considering the development of modern supply chains of multichannel trade in terms of their structural construction and logistics, we can conclude that there are less trade and intermediary links in the new chains.

This is due to the very specifics of the empirical market genesis of the supply chains of multichannel trade or online retail, the advantage of which over the stationary traditional commodity supply system is the lower price at the outlet of the chain. This is ensured by reducing the number of links (reducing the number of trade links) and enhancing the logistics of product distribution, which should ensure the movement of goods with minimal costs.

That is, we can state the transformation of the principles of design and management of multichannel supply chains, the development of which in the modern period and in the future requires strengthening the theoretical and methodological basis of multichannel trade logistics. This allows us to update and designate new directions for the synthesis and development of multichannel supply chains, for which the new methodological basis should be done.

2. Starting from the previous conclusion, we note that in the modern period of multichannel development of trade, it is not only the formation of a new configuration of supply chains with a new parity of production, trade, and logistics. Moreover, there is an expansion of the role of logistics in the development of multichannel supply chains.

At the same time, logistics itself is experiencing the increasing influence of digitalization, which has two main areas: automation of business processes of delivery at the digitalization level of all logistics services (transportation, loading and unloading, warehouse, etc.) and building new business models of goods and sales cooperation, innovation and operational basis of which relies on digital technology. It is the construction of new business models and the logistic transformation of business processes that form the institutional basis of modern digital technologies, the acceleration of which will allow overcoming the "catching up" character of modern logistic systems in the domestic economy [3]. 
With the general growth of the role of logistics as an infrastructure and technological basis of multichannel retail, many options arise in which logistics grows out of online business or online - trade becomes derivative and complements the logistics operator [14].

Russian online suppliers KupiVip and Lamoda are increasing their investments in building an autonomous logistics service and outsourcing logistics of their direct competitors, leaving them with marketing and sales management. From our point of view, these companies "buy" their growth, creating barriers to entering the market through capital-intensive investments, which may be quite risky for other companies.

American online retailer Amazon also actively develops autonomous logistics, opens fulfillment centers, and constantly experiments with logistics innovations, bringing the parameters of logistics services to "day-to-day" delivery. That is, logistics is becoming part of the product and service offer, complementing the core business of online shopping operators.

A reverse example is the emergence of marketplaces based on European commercial logistics operators, who were the first in Europe to implement the scalable marketplace model as an organic part of their mail-order business. Thus, in Germany, the marketplace of the logistic operator DHL (43.7\% in the market of mail items) developed and went beyond the limits of the domestic market.

The development of the e-commerce direction of the national postal operator of Austria allowed an increase in the volume of mail-order business, whose share in the market for shipments with goods or products reached 76\% versus 12.5\% for DPD in 2015 [15].

Thus, the development of marketplaces in the commercial logistics of European postal operators, as well as the creation of logistic units at Russian and foreign online retailers, is an indicator that in the multichannel trade system, logistics and sales effectively complement each other, both at strategic and operational levels. This kind of diversification provides increased market sustainability of the business.

In stationary trade, the transfer of wholesale business to logistics (3PL) occurred mostly not as an attempt to diversify - to supplement the wholesale direction, but as a way to remain on the market in the context of the abolition of the traditional business distribution model [13].

In online retail, such an opportunity is achieved today precisely because of the increasing role and importance of logistics, which are provided to a greater degree by technological development of logistics than by its infrastructural growth, which requires no less investment than traditional trade.

It is important to note that the institutional and market aspect of digitalization of supply chains disclosed in this study as the main one is globally characterized by the processes of integrating digital platforms into interconnected ecosystems. This process stimulates the launch of digital platforms of a new generation, geographically covering various markets, enterprises, which provides end-to-end control of the perimeter of value-added chains [20].

3. In the 1990-2000s, the scientific development of logistics in Russia took place mainly under the sign of its theoretical conceptualization, the formation and consolidation of the theoretical basis. Being formed as a general scientific direction, and not accurately identifying the range of tasks being solved, logistics has incorporated such areas as general systems theory, operations research, cybernetics, and forecasting.

At the same time, the theoretical basis of logistics developed not only in the spectrum of instrumental solution of practical problems, but in the spectrum of theoretical description of the trajectory of the market evolution of commodity distribution systems during transformation of trade and models of commodity and sales cooperation of the economic spheres of reproduction and circulation.

In the modern period, the depth and speed of changes occurring in multichannel trade form new vectors of progressive transformation and development of logistics, forming new 
classification signs of its division. Based on this, we can conclude that advanced scientific research in logistics will be characterized by some dialectical contradictions. On the one hand, it is necessary to solve new problems of the logistic development of multichannel supply chains. On the other hand, the theoretical foundations of the synthesis of multichannel trade logistics systems are not fully developed in the system of domestic logistic knowledge. The rapid evolution of the latter into the format of seamless integrated trade (omnichannel) complicates this task even more.

This allows us to conclude that modern research in logistics should be of utilitarian and instrumental nature, not theoretical. At the same time, the theory of logistics itself should reflect the evolutionary update of progressive market practice in its most radicalized patterns $[2,10,11]$. Today, the logistics of e-commerce grows with various innovations, for example, at the level of logistics of the last mile, where various startups are actively developing, for example, crowdsourcing platforms for order consolidation, various online aggregators, etc.

4. When drawing a parallel between stationary trade and online retail, it is important to note that within the framework of these product distribution systems, the role and importance of logistics has changed significantly.

In the modern period, logistics is not only an important technological basis for the development of online commerce. It is, above all, a driver and condition for its development. Despite the variety of product offers, especially characteristic for online retail (an endless retail shelf), its development is stimulated by services and not by the growth of product offers.

In our opinion, in the future, logistics will only strengthen its position in the business model of multichannel retail. The development of innovations in terms of logistics services will form competitive advantages, which are basic or key in the current phase of the market cycle.

In addition, digital logistics and its technological development create new risks for the further redistribution of the market under conditions when a significant part of its digital transformation processes is concentrated in startups. This enhances the risks of replacing traditional shipping business with digital platforms that will offer automated and digitized logistics solutions, demonstrate greater operational flexibility and user-friendly interface [21]. In the modern period, traditional European logistics operators are striving to prepare for this and are working out preventive solutions, preparing for competition with digital freight logistics platforms.

5. The empirical aspect of the development of logistics in multichannel supply chains is characterized by a number of innovations, the theoretical representation of which in modern logistics researches requires a significant expansion of the existing conceptual apparatus.

There is an increase in the logistics perimeter of supply chains: long-distance logistics, fulfillment, and last-mile logistics. Logistics now plays a dominant role in multichannel supply chains. All this forms a fundamentally new mechanics of product distribution, the theoretical representation of which in logistic science requires a more adequate description.

There is not just a complication, but the formation of new concepts, such as "digital transport", which is understood as "the system integration of intelligent communication technologies between the user, the vehicle, the traffic management system, and the infrastructure, the formation of new through digital technologies of the transportation process" [4].

In the consumer segment of the commodity market, the following concepts require the development and clarification:

- multichannel supply chain;

- omnichannel supply chain;

- automated delivery channel; 
- service providers (vendors, fulfillment providers) in the logistic sense of the interpretation of this concept;

- and etc.

These terms form a new conceptual apparatus for describing a fundamentally different mechanics of sales organization, which differs from linear supply chains.

\section{Discussion}

We believe that in the theory of logistics, new concepts should be formed, reflecting the new balance of complementarity between offline and online in the multichannel logistics system - omnichannel sales. This is due to the fact that in the last decade, there has been a change in the business model of trading, within which offline stores will gradually turn into a point of support for online sales. This trend is characteristic not only for the Russian but also for foreign markets. As a result of the change in the business model, the "Technosila" retail chain records "a rapid growth in the share of customers who place orders on the site and pick it up in the store: at present, approximately $70-75 \%$ of online customers are operating according to this scheme (the indicator depends on the product category, season, etc.)" $[25$, p.9].

Chinese online retailer Alibaba buys nearly $20 \%$ of shares of the regional chain of electronics stores Suning Online-to-Offline $(\mathrm{O} 2 \mathrm{O})$, which indicates a tight integration of digital and offline retail and will allow more efficient delivery of electronics and home appliances to the small cities of China and the countryside.

This indicates the formation of a new sales organization model in which various online shopping opportunities are complemented by offline trading and logistics infrastructure. Their synergy is characterized by a fundamentally new balance of digital technology and offline, which in the modern period was not reflected in the system of logistics research.

Developing the previous statement, we note that despite the growing role of transformation of the sales organization business model and the transition to multichannel and further omnichannel trade, the market cycle of their development is also finite. At the same time, in the modern period, there are certain signs of the devirtualization of business models, oriented towards the production of additional values. Online suppliers Lamoda and KupiVip actively invest in the development of logistics infrastructure, online retailer Amazon from a seller becomes a manufacturer and invests in offline retail chains, UBER creates its own fleet, Internet holding Ulmart develops large-scale multi-level logistics infrastructure, offering a highly efficient delivery format (UlmartStore ) for any online sellers [20].

In the current phase of development, digital businesses, making weak competition to materialized services for meeting needs of customers, are becoming integrated services, but not interface ones. The digital trend in the development of the online market has ensured the speculative growth of e-commerce, the growth of digital trading and service startups, which are now becoming cheaper and no longer a decisive competitive advantage. Gradually, digital products and IT solutions, which now are the basis of market capitalization in the online business, are transformed into service additions to the physical product. Materialized logistic, service, infrastructure and other advantages will be more dominant than market-matched (competition) opportunities of replicable business models of online sales.

We draw attention to the fact that the development of own logistics infrastructure in online retail is not only a way to strengthen the financial model but also a barrier to entry into the market. That is, in the new phase of the market cycle, the materialization of online trading services will be an important factor in enhancing the competitive advantages of its operators. 
At the first stage of development of online trading, the driver of its growth and differentiation relative to stationary retail was a new business model. At the second stage, the current trend update in consumer behavior made the inevitable transition to a seamless integrated omnichannel sales model. The expansion of the competitive environment of the market, the increase in the number of online retailers and various modifications of online stores has led to an increase in competitive tension in the process of replicating business models, the growth of product offerings and scaling businesses. Trading companies began to look for new ways of market destinguishing from competitors, one of which is the development of services, investments in IT solutions, trade and logistics infrastructure $[16,17]$.

This trend should have a detailed theoretical analysis in logistics research devoted to the analysis of modern features of the development of market infrastructure of the multichannel trade. Such studies should have a new methodological basis, a methodological platform, and no doubt a new conceptual apparatus.

\section{Conclusions}

In general, the basic, in our opinion, features of the further theoretical development of logistics, determined by the evolutionary transition of domestic retail to the multichannel sales model and the qualitative development of this model, are indicated.

The high speed and depth of the qualitative institutional and market transformation of stationary trade and Internet retail, its operational and technological in the conditions of the active development of outsourcing services of logistics service providers in the Internet trade system form the specifics of the functioning of the product distribution system for traditional trade and online trading. The results of its scientific and practical analysis and justification for the future expand the possibilities of forming a conceptually new model for the balanced development of the logistics ecosystem of multichannel trade in Russia.

The wide choice in the digital environment in comparison with the physical one allows producing a product offer that is not limited in scope and geography, which ensures leading positions in the segment by product, marketing, and logistics. Everywhere replicated attempts to duplicate the product and service functions of a market leader turn out to be ineffective, and competition in the area of grocery supply requires the development and/or formation of new ways of meeting needs, for example, in product logistics. Innovations in logistics, the achievement of a larger scale of the infrastructure of the physical distribution of goods, the formation of a progressive customer experience - all this constitutes a resource for the further competitive growth of multichannel supply chains [19].

Thus, the relatively chaotic development of multichannel retail and not limited replication of digital startups with a similar product offer or service stimulate the search for additional customer value. Hence the reason for the increasing importance of logistics and product distribution in multichannel supply chains, where the hypertrophied growing competition of thousands of identical digital startups allows us to consider logistics as a relevant and practically central way of differentiated distinguishing, the full implementation of which requires significant investments in logistics infrastructure. Companies that do not have such resource capabilities are subject to fierce competition.

Digital change in supply chains, stimulating the formation of a functional application of logistics in a multi-format multichannel retail service system, forms a new empirical basis and non-linear trajectory of the accelerated market evolution of Internet logistics and multichannel supply chains, new directions of scientific and practical development of logistics and a deeper differentiation of its classification basis are of great theoretical, methodological, and practical importance. 
Thus, the transformation of supply chains in the process of transition to the multichannel sales model forms a new vector of scientific research in the logistics of ecommerce, its theorization and instrumental development, and the definition of empirical markers of the new concept of logistic knowledge.

\section{References}

1. A.U. Albekov, Modern logistics technologies and strategies (shopping complex), monograph (RSUE, Rostov n/D, 2013)

2. V.V. Baginova, World of Transport 12-5(54), 112-115 (2014)

3. V.V. Borisova, Foresight of logistics: the future of logistics through the eyes of young scientists, Collection of materials of the international foresight session 1, 53-58 (2018)

4. G.V. Bubnova, International Journal of Open Information Technologies 5-3, 73 (2017)

5. E.N. Vetrova, Scientific journal NRU ITMO, Series: Economics and Environmental Management 3, 65-70 (2016)

6. A.A. Voronova, Young scientist: challenges and prospects. Collection of papers based on the X International Scientific Practical Conference 1, 334-338 (2016)

7. V. Gasparyan, Retail\&Loyalty 7(52), 34-40 (2015)

8. E. Krivosheya, Retail\&Loyalty 3(6), 51-57 (2017)

9. C. Christensen, M. Clayton, Seeing What's Next: Using the Theories of Innovation to Predict Industry Change (Alpina Publisher, Moscow, 2017)

10. C. Christensen, M. Clayton, The Innovator's Dilemma: When New Technologies Cause Great Firms to Fail (Alpina Publisher, Moscow, 2017)

11. D.S. Lopatkin, Economy and Entrepreneurship 8-1(61-1), 1148-1152 (2015)

12. E.A. Mamaev, Bulletin of the Rostov State University of Economics "RINH" 4(52), 17-25 (2015)

13. E.A. Mamaev, E.S. Valchuk, Proceedings of the Rostov State Transport University 4, 51-55 (2015)

14. E.A. Mamaev, A.N. Guda, Competitiveness in the global world: economy, science, technology 9-3(25), 72-76 (2016)

15. M.V. Mikhaylyuk, Financial Studies 4(53), 244-249 (2016)

16. M.V. Mikhaylyuk, E-commerce logistics as a factor in the development of multichannel supply chains in the product distribution system of the consumer market, monograph (FSBEI of HE RSTU, Rostov on Don, 2018)

17. M.V. Mikhaylyuk, Accounting and statistics 4, 131-137 (2016)

18. M.V. Mikhailyuk, Competitiveness in the global world: economy, science, technology 7, 48-52 (2018)

19. A.G. Nekrasov, A.S. Sinitsyna, Power of Systems 3(4), 12 (2017)

20. O. Ponorets, A. Zakomirny, Logistics 8(129), 32-35 (2017)

21. A.A. Ryazanov, Bulletin of Moscow Witte University, Series 1: Economics and Management 2(21), 21-30 (2017)

22. V.I. Sergeev, Logistics and supply chain management 6(83), 3-14 (2017)

23. V.I. Sergeev, I.M. Dutikov, Logistics and supply chain management 2(79), 87-97 (2017)

24. I. Timchenko, Retail\&Loyalty 2(56), 9 (2016) 